\title{
A New Neuronal Cell Protecting Substance, Lavanduquinocin, Produced by Streptomyces viridochromogenes
}

\author{
Kazuo Shin-ya, Shintaro Shimizu, Toshihiro Kunigami, Keiko Furihata, \\ Kazuo Furihata ${ }^{\dagger}$ and Haruo Seto*
}

Institute of Cellular and Molecular Biosciences, University of Tokyo,

${ }^{\dagger}$ Division of Agriculture and Agricultural Life Sciences, University of Tokyo, Bunkyo-ku, Tokyo 113, Japan

(Received for publication February 16, 1995)

\begin{abstract}
A new neuronal cell protecting substance, lavanduquinocin was isolated from Streptomyces viridochromogenes 2942-SVS3. It consists of a carbazole skeleton with an ortho quinone function and a cyclolavandulyl moiety. Lavanduquinocin protected neuronal hybridoma N18-RE-105 cells from L-glutamate toxicity with $\mathrm{EC}_{50}$ value $15.5 \mathrm{nM}$.
\end{abstract}

It has been well accepted that the excitatory amino acid, L-glutamate acting as a neurotransmitter in the major part of brain, induces neuronal cell death after brain-ischemic attack ${ }^{11}$. L-Glutamate proved to generate oxygen radicals through a variety of intracellular cascades in such events ${ }^{2}$. Under some conditions, brainischemia injury is prevented by free radical scavengers ${ }^{3)}$. In the course of our screening for substances which protect neuronal hybridoma N18-RE-105 cells from the L-glutamate toxicity, we isolated carquinostatin $\mathrm{A}^{4}$. Further investigation has resulted in the isolation of a novel compound named lavanduquinocin (1, Fig. 1).

\section{Materials and Methods}

\section{Taxonomic Studies}

An organism designated 2942-SVS3 was isolated from a soil sample collected in Adachi-ku, Tokyo, Japan. Its characterization and identification were carried out mainly according to BERGEY's Manual ${ }^{5)}$ and the methods described by SHIRLING and GoTTLIEB ${ }^{6}$. For the evaluation of cultural characteristics, the strain was incubated for 14 days at $27^{\circ} \mathrm{C}$. Cell wall composition was analyzed by the methods of BECKER et al. ${ }^{7}$.

\section{Spectral Analysis}

Mass spectra were recorded on a JEOL HX-110 spectrometer in the FAB mode using $m$-nitrobenzyl alcohol as a matrix and polyethylene glycol as internal standard. UV and visible spectra were recorded on a Hitachi U-3210 spectrophotometer and IR spectra were recorded on a Jasco A-102 spectrophotometer. ${ }^{1} \mathrm{H}$ and ${ }^{13} \mathrm{C}$ NMR spectra were obtained on a JEOL JNM-A500 spectrometer in $\left(\mathrm{CD}_{3}\right)_{2} \mathrm{SO}$ solution. Chemical shifts are given in ppm using TMS as internal standard.

\section{Preparation of $(R)$ - and $(S)$-MTPA Esters}

$(R)$ - and $(S)$-MTPA esters of 1 were prepared according to the reported procedures ${ }^{8)}$. To a solution of $1(1.5 \mathrm{mg})$ in chloroform $(1.5 \mathrm{ml})$ and pyridine $(100 \mu \mathrm{l})$ was added (+)- or (-)-MTPA chloride (30 $\mathrm{mg})$, and the solution was stirred at room temperature for 3 hours. Methanol $(2 \mathrm{ml})$ was then added, and after stirring for 5 minutes, the solvent was evaporated. The residue was subjected to preparative TLC (Merck, Kieselgel 60, $\mathrm{F}_{254}$, $\left.\mathrm{CHCl}_{3}-\mathrm{MeOH}, 50: 1\right)$ affording a pure sample of the $(R)$ - or $(S)$-MTPA ester of $\mathbf{1}$.

\section{Cell and Cell Culture}

N18-RE-105 hybrid cells ${ }^{9}$ (mouse neuroblastoma clone N18TG- $2 \times$ Fisher rat 18-day embryonic neural retina) were grown in a DuLbecco's modified EAGLE's

Fig. 1. Structures of lavanduquinocin (1) and carquinostatin A.
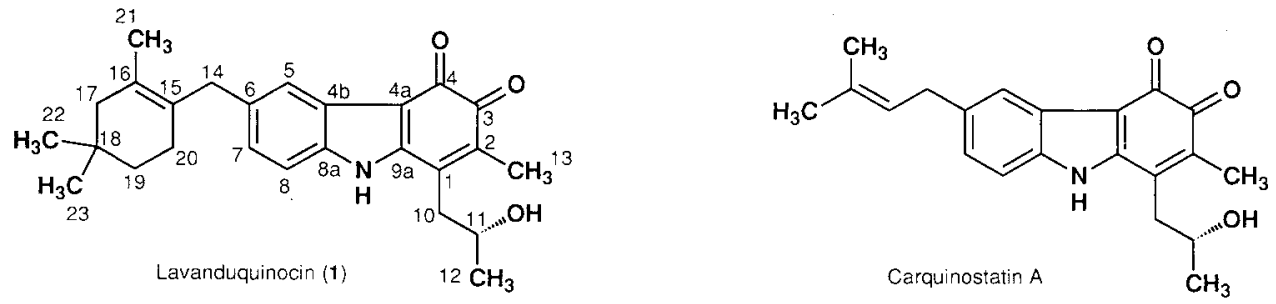

Dedicated to Professor SATOSHI ŌMURA's 60th birthday. 
Table 1. Cultural characteristics of strain 2942-SVS3.

\begin{tabular}{llll}
\hline & Aerial mycelium & \multicolumn{1}{c}{ Reverse side color } & Soluble pigment \\
\hline Sucrose- nitrate agar & Not formed & Light orange & None \\
Glucose - asparagine agar & Green color series & Light orange light reddish orange & None \\
Glycerol - asparagine agar & Green color series & Light orange & None \\
Inorganic salts - starch agar & Green color series & Pale yellowish orange & None \\
Tyrosine agar & Green color series & Reddish brown & Brownish white \\
Nutrient agar & Not formed & Dull red & None \\
Yeast-malt agar & Not formed & Pale brown & None \\
Oatmeal agar & Green color series & Pale reddish orange & None \\
\hline
\end{tabular}

Fig. 2. Scanning electron micrograph of spore chains of strain 2942-SVS3.

Bar represents $0.5 \mu \mathrm{m}$.

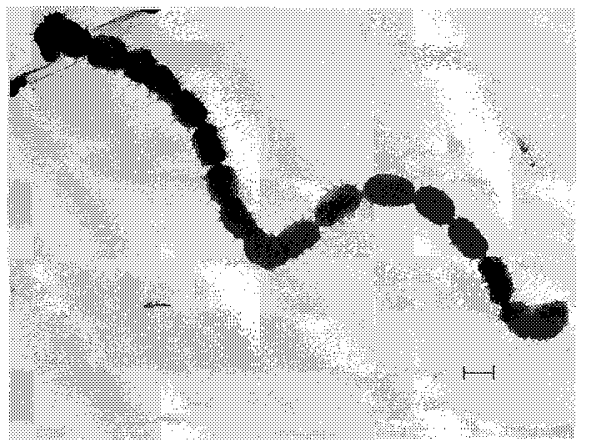

medium supplemented with $0.1 \mathrm{~mm}$ hypoxanthine, 0.04 $\mathrm{mm}$ aminopterin, $0.14 \mathrm{~mm}$ thymidine and $10 \%$ heatinactivated fetal calf serum. The cells were cultured in a humidified atmosphere of $5 \% \mathrm{CO}_{2}$ in air at $37^{\circ} \mathrm{C}$. For cytotoxicity studies, cells were plated at $6.25 \times 10^{3}$ cells/ $\mathrm{cm}^{2}$. After culturing for 24 hours, the medium was removed and replaced with a medium containing $10 \mathrm{~mm}$ L-glutamate. Cytotoxicity was monitored after 24 hours by a phase-contrast microscope and quantified by the measurement of the cytosolic enzyme, lactate dehydrogenase (LDH), released into the culture medium from degenerated cells ${ }^{10}$.

\section{Results}

\section{Taxonomy}

The substrate mycelium of strain 2942-SVS3 did not fragment. The aerial mycelium irregularly branched on the long main stem and terminated spirals $(3 \sim 7$ rotation), forming spore chains with $10 \sim 50$ spores per chain. The spores were ellipsoidal $(0.45 \sim 0.5 \times 0.6 \sim 0.8$ $\mu \mathrm{m}$ ) and their surface was spiny (Fig. 2). The culture showed no special morphology such as sporangia, whirls or sclerotia. Whole-cell hydrolysate of strain 2942-SVS3 contained LL-diaminopimelic acid. Accordingly, the cell wall of the strain was classified as type $\mathbf{I}$.

The cultural and physiological properties of strain
Table 2. Physiological characteristics of strain 2942-SVS3.

\begin{tabular}{lc}
\hline Temperature range for growth $\left({ }^{\circ} \mathrm{C}\right)$ & $20 \sim 45$ \\
Production of melanoid pigment & \\
Tyrosine agar & + \\
Peptone - yeast - iron agar & \pm \\
Tryptone - yeast broth & + \\
Hydrolysis of starch & - \\
Liquefaction of gelatin & - \\
Peptonization of milk & - \\
Coagulation of milk & + \\
Reduction of nitrate & \\
Utilization of carbon source & + \\
D-Glucose & + \\
L-Arabinose & + \\
D-Xylose & + \\
D-Fructose & + \\
Sucrose & + \\
L-Rhamnose & + \\
Raffinose & + \\
Inositol & + \\
D-Mannitol & + \\
\hline
\end{tabular}

2942-SVS3 are summarized in Tables 1 and 2, respectively. Mature aerial mycelia corresponded to the green color series. The reverse side of the colony was light orange to light reddish orange. No soluble pigment except melanoid pigment was observed. The results of these morphological and chemotaxonomic studies indicate that strain 2942-SVS3 belongs to the genus Streptomyces. Among the species of Streptomyces described in BERGEY's Manual, strain 2942-SVS3 appeared to be most closely related to Streptomyces viridochromogenes except the reverse color and soluble pigments. Thus, the strain 2942-SVS3 was identified as Streptomyces viridochromogenes 2942-SVS3.

\section{Fermentation}

The seed medium consisted of soluble starch $1.0 \%$, molasses $1.0 \%$, meat extract $1.0 \%$ and polypepton $1.0 \%$ (pH 7.2 before sterilization). Seed tubes containing 15 $\mathrm{ml}$ of the medium were inoculated with a stock culture of $S$. viridochromogenes 2942-SVS3 maintained on a BENNET's agar slant, and were incubated on a reciprocal shaker at $27^{\circ} \mathrm{C}$ for 2 days. The seed culture at $2 \%$ was 
transferred to $500-\mathrm{ml}$ Erlenmeyer flasks containing $100 \mathrm{ml}$ of a medium consisting of soluble starch $2.5 \%$, soybean meal $1.5 \%$, dried yeast $0.2 \%$ and calcium carbonate $0.4 \%$ ( $\mathrm{pH} 6.2$ before sterilization). The flasks were incubated on a rotary shaker at $27^{\circ} \mathrm{C}$ for 5 days.

\section{Isolation}

The fermentation broth ( 2 liters) was centrifuged to give a mycelial cake, which was extracted with $500 \mathrm{ml}$ of acetone. The extract was concentrated and the residue was extracted twice with ethyl acetate. The organic fraction was dried over $\mathrm{Na}_{2} \mathrm{SO}_{4}$, and concentrated to dryness. The oily residue was washed with $n$-hexane, and the residue was applied to a silica gel column $(100 \mathrm{ml})$, which was developed with chloroform - methanol $(50: 1)$. The active eluate was further purified by HPLC using PEGASIL ODS (Senshu-Pak, 20 i.d. $\times 250 \mathrm{~mm}$ ) with $90 \%$ methanol. The collected main peak was concentrated to dryness to give a reddish brown powder of 1 (4 mg).

\section{Physico-chemical Properties}

The physico-chemical properties of $\mathbf{1}$ are summarized in Table 3. The molecular formula of $\mathbf{1}$ was established as $\mathrm{C}_{26} \mathrm{H}_{31} \mathrm{NO}_{3}$ by high-resolution FAB-MS. UV and visible spectra revealed the presence of a chromophore in 1 identical or similar to that in carquinostatin $\mathrm{A}^{4)}$ (Fig. 1). IR absorptions at 1645 and $1620 \mathrm{~cm}^{-1}$ implied the presence of a quinone carbonyl function.

\section{Structure Elucidation}

The ${ }^{1} \mathrm{H}$ NMR spectrum and tabulated ${ }^{13} \mathrm{C}$ NMR spectral data are shown in Fig. 3 and Table 4, respectively.

The phase-sensitive DQF spectrum revealed the presence of a 1,2,4-trisubstituted benzene ring. A

Table 3. Physico-chemical properties of lavanduquinocin (1).

\begin{tabular}{ll}
\hline Appearance & Reddish brown powder \\
MP & $157 \sim 158^{\circ} \mathrm{C}$ \\
Molecular formula & $\mathrm{C}_{26} \mathrm{H}_{31} \mathrm{NO}_{3}$ \\
HRFAB-MS $(m / z)$ & $406.2394(\mathrm{M}+\mathrm{H})^{+}$ \\
$\quad$ Found & 406.2382 \\
$\quad$ Calcd & $232(17,500), 269(15,900)$, \\
UV $\lambda_{\max }^{\mathrm{MeOH}} \mathrm{nm}(\varepsilon)$ & $429(3,100)$ \\
\multicolumn{1}{l}{$\lambda_{\max }^{\mathrm{MeOH}+\mathrm{NaOH}} \mathrm{nm}(\varepsilon)$} & $244(16,400), 288(16,300)$, \\
& $472(4,300)$ \\
IR $v_{\max }(\mathrm{KBr}) \mathrm{cm}^{-1}$ & $3450,3220,1660(\mathrm{sh})$, \\
& $1640(\mathrm{sh}), 1615$ \\
\hline
\end{tabular}

Table $4 .{ }^{13} \mathrm{C}$ and ${ }^{1} \mathrm{H}$ chemical shifts of lavanduquinocin (1) in $\mathrm{DMSO}-d_{6}$

\begin{tabular}{ccc|ccc}
\hline No. & $\delta_{\mathrm{C}}$ & $\delta_{\mathrm{H}}$ & No. & $\delta_{\mathrm{C}}$ & $\delta_{\mathrm{H}}$ \\
\hline 1 & 140.1 & & 11 & 65.9 & 3.95 \\
2 & 134.3 & & 12 & 23.7 & 1.23 \\
3 & 183.9 & & 13 & 12.1 & 1.91 \\
4 & 172.5 & & 14 & 38.4 & 3.41 \\
$4 \mathrm{a}$ & 110.7 & & 15 & 127.3 & \\
$4 \mathrm{~b}$ & 126.2 & & 16 & 125.6 & \\
5 & 119.4 & 7.63 & 17 & 45.6 & 1.78 \\
6 & 136.7 & & 18 & 28.9 & \\
7 & 124.5 & 6.98 & 19 & 35.4 & 1.24 \\
8 & 113.4 & 7.40 & 20 & 26.8 & 1.84 \\
$8 \mathrm{a}$ & 136.0 & & 21 & 19.6 & 1.73 \\
$9 \mathrm{a}$ & 146.7 & & 22,23 & 28.1 & 0.84 \\
10 & 37.7 & 2.74 & & & \\
\hline
\end{tabular}

Fig. 3. ${ }^{1} \mathrm{H}$ NMR spectrum of $\mathbf{1}$ in DMSO- $d_{6}$.

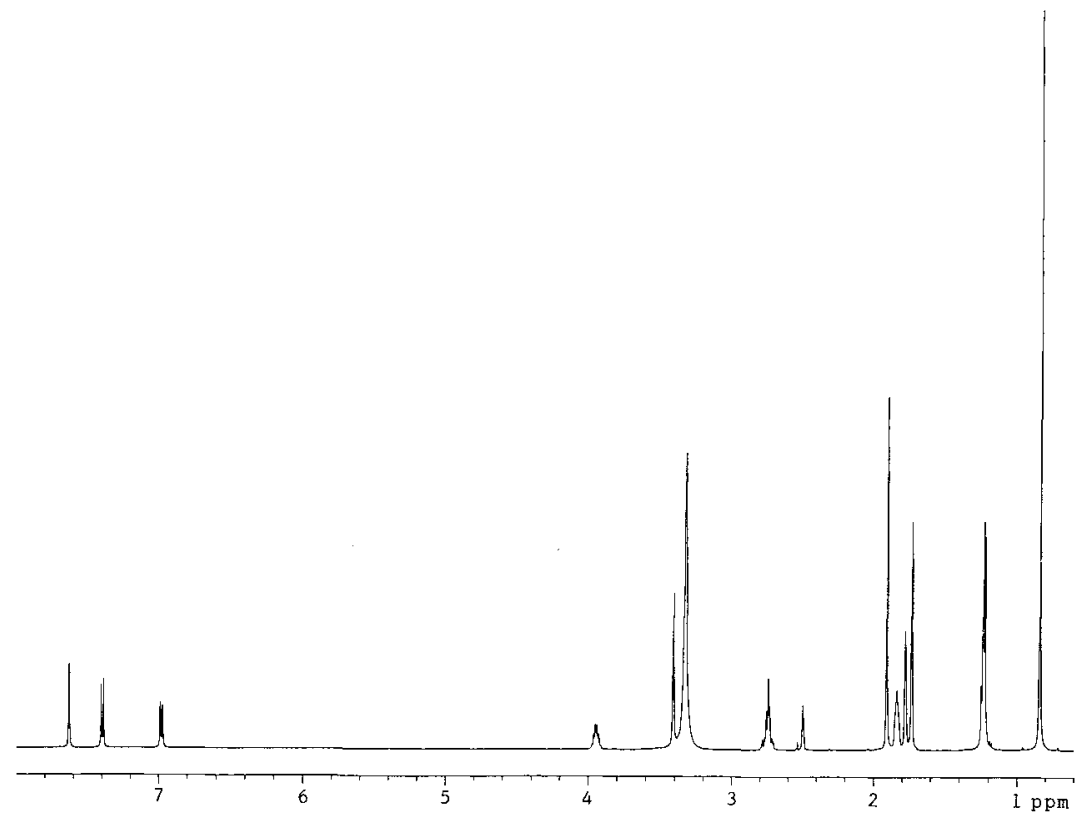


Fig. 4. Partial structures of 1.

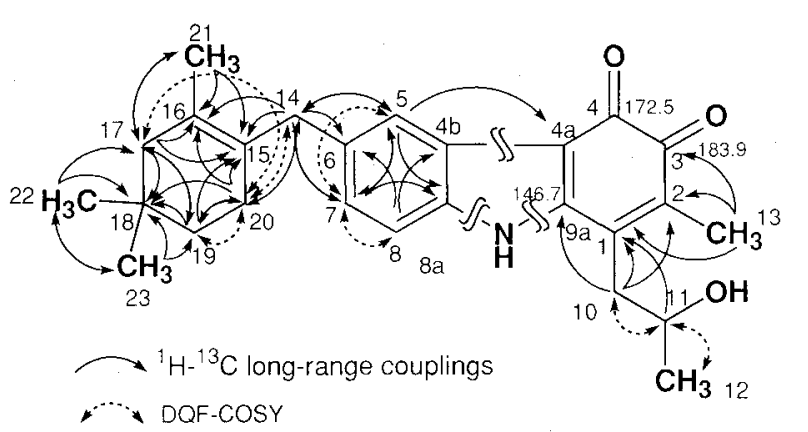

methylene proton signal $19-\mathrm{H}(1.24 \mathrm{ppm})$ was coupled to a methylene proton signal $20-\mathrm{H}(1.84 \mathrm{ppm})$ which showed long-range couplings with methylene protons $17-\mathrm{H}(1.78 \mathrm{ppm})$ and $14-\mathrm{H}(3.41 \mathrm{ppm})$. Singlet methyl protons $22,23-\mathrm{H} \quad(0.84 \mathrm{ppm}, 6 \mathrm{H})$ showed ${ }^{1} \mathrm{H}-{ }^{13} \mathrm{C}$ long-range couplings to $\mathrm{C}-17$ (45.6 ppm), C-18 (28.9 ppm) and $\mathrm{C}-19$ (35.4 ppm) in the HMBC spectrum. In addition, an allylic methyl proton $21-\mathrm{H}(1.73 \mathrm{ppm})$ was coupled to $\mathrm{C}-15$ (127.3 ppm), C-16 (125.6 ppm) and C-17 (45.6 ppm). The connectivity between C-14 (38.4 ppm) and C-15 was also confirmed by the long-range couplings from $14-\mathrm{H}$ to $\mathrm{C}-15, \mathrm{C}-16$ and $\mathrm{C}-20$ (26.8 ppm). These results indicated the presence of a cyclolavandulyl moiety $^{11)}$ (Fig. 4). Aromatic protons 5-H (7.63 ppm) and $7-\mathrm{H}(6.98 \mathrm{ppm})$ showed the long-range couplings to C-14. Thus, the cyclolavandulyl moiety was linked to the C-6 (136.7 ppm) position of the 1,2,4-trisubstituted benzene ring explained above. Other ${ }^{1} \mathrm{H}-{ }^{13} \mathrm{C}$ long-range couplings revealed by the $\mathrm{HMBC}$ experiments are shown in Fig. 4.

Another substructure was determined as follows. The sequence from methylene protons $10-\mathrm{H}(2.74 \mathrm{ppm})$ to methyl protons $12-\mathrm{H}(1.23 \mathrm{ppm})$ through an oxymethine proton $11-\mathrm{H}(3.95 \mathrm{ppm})$ revealed the presence of a 2 hydroxypropyl residue. The terminal methylene signal of this unit (10-H) was long-range coupled to aromatic carbons C-1 (140.1 ppm), C-2 (134.3 ppm) and C-9a (146.7 ppm). An aromatic methyl proton resonance $13-\mathrm{H}$ (1.91 ppm) was coupled to aromatic carbons C-1, C-2 and a quinone carbonyl carbon C-3 (183.9 ppm). Since the ${ }^{13} \mathrm{C}$ chemical shift of $\mathrm{C}-9 \mathrm{a}(146.7 \mathrm{ppm})$, which was para to a carbonyl carbon $\mathrm{C}-3$, was too high to be assigned to a quinone carbonyl carbon, the quinone system was concluded to be an ortho system; this function being supported by the UV and visible spectra of 1 . Thus, the other quinone carbonyl carbon C-4 (172.5 ppm) and the remaining aromatic carbon C-4a (110.7 ppm) were assigned as shown in Fig. 4. The linkage between these
Fig. 5. Preventive effect of lavanduquinocin and carquinostatin A on glutamate toxicity in N18-RE-105 cells.

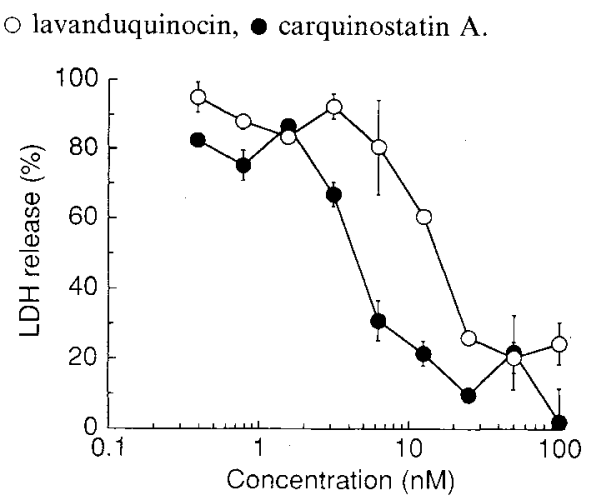

two substructures was established by long-range coupling of $5-\mathrm{H}$ to $\mathrm{C}-4 \mathrm{a}$, and by comparison of the ${ }^{13} \mathrm{C}$ chemical shifts of 1 with those of carquinostatin A.

The absolute stereochemistry at C-11 position of 1 was determined to be $R$ by the modified MosHER method ${ }^{8,12)}$. Thus, $10-\mathrm{H}$ and $13-\mathrm{H}$ resonated at upper field in the $(S)$-ester than in the $(R)$-ester $(\Delta \delta,-0.05 \mathrm{ppm}$ and $-0.03 \mathrm{ppm}$, respectively. $\Delta \delta=\delta_{S}-\delta_{R}$ ). Moreover, $12-\mathrm{H}$ appeared upfield for the $(R)$-ester than for the $(S)$-ester $(\Delta \delta,+0.02 \mathrm{ppm})$. Structurally 1 with a carbazole skeleton incorporating an ortho quinone function is related to carquinostatin $\mathrm{A}$ and carbazoquinocins ${ }^{13)}$.

\section{Biological Activity}

In the evaluation system we employed ${ }^{14,15)}, 1$ and carquinostatin A decreased the L-glutamate toxicity to N18-RE-105 cells with $\mathrm{EC}_{50}$ values $15.5 \mathrm{nM}$ and $4.3 \mathrm{nM}$, respectively (Fig. 5). Apoptotic cell death of N18-RE-105 cells induced by buthionine sulfoximine (BSO) as a result of depletion of glutathione, an endogenous reducing agent ${ }^{16}$, was also suppressed by 1 at concentrations higher than $12.5 \mathrm{~nm}$. This toxicity of BSO is considered to involve oxygen radicals.

\section{Discussion}

Lavanduquinocin showed a strong activity to suppress the L-glutamate toxicity in neuronal hybridoma N18RE-105 cells. It consists of a carbazole nucleus with an ortho quinone function and a cyclolavandulyl moiety, and structurally related to carquinostatin A, a metabolite of Streptomyces exfoliatus. It is interesting to note that they possess at the same position a monoterpenoidal side chain, which is rarely found in the metabolites of Streptomyces.

The L-glutamate toxicity to N18-RE-105 cells is calcium dependent ${ }^{17)}$ and mainly caused by inhibition of cystine uptake ${ }^{15)}$. This toxicity is blocked by mem- 
brane depolarization caused by, for example, ouabain or treatment of high concentrations of $\mathrm{KCl}^{18}$ ), and is blocked by reducing agents such as dithiothreitol and glutathione ${ }^{14)}$. Since lavanduquinocin suppressed the BSO toxicity, it presumably acts as a reducing agent instead of glutathione in N18-RE-105 cells. Thus the mode of action of lavanduquinocin is thought to be mainly dependent on its antioxidative activity. Further investigation on its biological activity is now under way.

\section{Acknowledgments}

This work was supported in part by a Grant-in Aid for Encouragement of Young Scientists, The Ministry of Education, Science and Culture, Japan to K. S.

\section{References}

1) Chor, D. W.: Cerebral hypoxia: some approaches and unanswered questions. J. Neurosci. 10: 2493 2501, 1990

2) Coyle, J. T. \& P. Puttfarcken: Oxidative stress, glutamate, and neurodegenerative disorders. Science 262: $689 \sim 695,1993$

3) Kinouchi, H.; C. J. Epstein, T. Mizui, E. Carlson, S. F. CHEN \& P. H. Chan: Attenuation of focal cerebral ischemic injury in transgenic mice overexpressing $\mathrm{CuZn}$ superoxide dismutase. Proc. Natl. Acad. Sci. U.S.A. 88: $11158 \sim 11162,1991$

4) Shin-ya, K.; M. Tanaka, K. Furihata, Y. Hayakawa \& H. SETO: Structure of carquinostain A, a new neuronal cell protecting substance produced by Streptomyces exfoliatus. Tetrahedron Lett. 34: 4943 4944, 1993

5) Locci, R.: Streptomyces and related genera. In BERGEY's Manual of Systematic Bacteriology. Vol. 4. Ed., S. T. Williams et al., pp. $2451 \sim 2508$, Williams \& Wilkins, 1989

6) Shirling, E. B. \& D. Gottlieb: Methods for characterization of Streptomyces species. Int. J. Syst. Bacteriol. 16: 313 340, 1966

7) Becker, B.; M. P. LeChVAlier \& H. A. LechevalieR: Chemical composition of cell wall preparations from strains of various genera of aerobic actinomycetes. Appl. Microbiol. 13: 236 243, 1965

8) DALE, J. A. \& H. S. Mosher: Nuclear magnetic resonance enantiomer reagents. Configurational correlations via nuclear magnetic resonance chemical shifts of diastereomeric mandelate, $O$-methylmandelate, and $\alpha$ methoxy- $\alpha$-trifluoromethylphenylacetate (MTPA) esters. J. Am. Chem. Soc. 95: 512 519, 1973

9) Malouf, A. T.; R. L. SchnaAR \& J. T. Coyle: Characterization of glutamic acid neurotransmitter binding site on neuroblastoma hybrid cells. J. Biol. Chem. 20: $12756 \sim 12762,1984$

10) KOH, J. \& D. W. CHoI: Vulnerability of cultured cortical neurons to damage by excitotoxins: differential susceptibility of neurons containing NADPH-diaphorase. J. Neurosci. 8: 2153 2163, 1988

11) Imai, S.; K. Furihata, Y. Hayakawa, T. NoGuchi \& H. SETO: Lavanducyanin, a new antitumor substance produced by Streptomyces sp. J. Antibiotics 42: 1196 1198, 1989

12) Ohtani, I.; T. Kusumi, Y. Kashman \& H. Kakisawa: High-field FT NMR application of Mosher's method. The absolute configurations of marine terpenoids. J. Am. Chem. Soc. 113: 4092 4096, 1991

13) Tanaka, M.; K. Shin-ya, K. Furihata \& H. Seto: Isolation and structural elucidation of antioxidative substances, carbazoquinocins A to F. J. Antibiotics 48: $326 \sim 328,1995$

14) Miyamoto, M.; T. H. Murphy, R. L. SchnaAr \& J. T. COYLE: Antioxidants protect against glutamate-induced cytotoxicity in a neuronal cell line. J. Pharmacol. Exp. Ther. 250: $1132 \sim 1140,1989$

15) Murphy, T. H.; M. Miyamoto, A. Sastre, R. L. SCHNAAR \& J. T. COYLE: Glutamate toxicity in a neuronal cell line involves inhibition of cystine transport leading to oxidative stress. Neuron 2: $1547 \sim 1558,1989$

16) Kane, D. J.; T. A. Sarafian, R. Anton, H. Hahn, E. B. Gralla, J. S. Valentine, T. Örd \& D. E. Bredesen: Bcl-2 inhibition of neural death: Decreased generation of reactive oxygen species. Science 262: 1274 1277, 1993

17) Murphy, T. H.; A. T. Malouf, A. Sastre, R. L. SchnaAr \& J. T. COYLE: Calcium-dependent glutamate cytotoxicity in a neuronal cell line. Brain Res. 444: 325 332, 1988

18) Murphy, T. H.; R. L. SchnaAR, J. T. Coyle \& A. SASTre: Glutamate cytotoxicity in a neuronal cell line is blocked by membrane depolarization. Brain Res. 460: 155 160, 1988 